\title{
Ultrassonografia reprodutiva aplicada a ruminantes
}

\author{
Victor José Correia Santos
}

Universidade Estadual Paulista “Júlio de Mesquita Filho". Faculdade de Ciências Agrárias e Veterinárias - Campus de Jaboticabal.

ISSUE DOI: $10.3738 / 1982.2278 .1146$

A ultrassonografia é amplamente utilizada em Medicina Veterinária, tem um papel importante na avaliação de matrizes, reprodutores e conceptos, auxiliando o médico veterinário e o produtor nas tomadas de decisão referentes ao manejo e à estratégia reprodutiva. A ultrassonografia convencional (modo B) permite que seja feito o diagnóstico de prenhêz, estimativa da quantidade de fetos, avaliação da viabilidade fetal, além de poder ser utilizada como parte do exame andrológico, diagnosticando anormalidades testiculares e de glândulas acessórias. O modo Doppler, permite a avaliação do fluxo sanguíneo nos órgãos da reprodução e nos fetos. Com os recentes avanços proporcionados pela pesquisa, cada vez mais essa tecnologia tem expandido seu leque de possibilidades de uso na reprodução animal. A tecnologia de contraste por microbolhas aumenta a sensibilidade na detecção do sinal Doppler em animais obesos, vasos profundos ou órgãos com fluxo sanguíneo reduzido. A elastografia fornece informações sobre ecotextura e ecogenicidade, além da dureza do tecido avaliado. Essas informações são especialmente importantes, quando a palpação não é possível, ou quando ela não fornece informações suficientes para auxiliar o diagnóstico. Essas tecnologias têm sido muito pesquisadas na Medicina Veterinária de animais de companhia e ampliam os horizontes da ultrassonografia veterinária tendo um futuro promissor. No entanto, mais pesquisas são necessárias a fim de se estabelecer padrões para o uso dessas técnicas, bem como sua aplicabilidade na rotina veterinária, também, em ruminantes.

Palavras-chave: imaginologia, ultrassom, reprodução, ruminantes. 